\title{
Lightweight 3D Printed Concrete Beams Show an Environmental Promise: A Cradle-to-Grave Comparative Life Cycle Assessment
}

\section{Styrmir Gislason}

University of Southern Denmark

\section{Simon Bruhn}

University of Southern Denmark

Luca Breseghello

University of Southern Denmark

\section{Burak Sen}

University of Southern Denmark

\section{Gang Liu}

University of Southern Denmark

Roberto Naboni ( $\square$ ron@iti.sdu.dk)

University of Southern Denmark https://orcid.org/0000-0001-9647-0426

\section{Research Article}

Keywords: 3D Concrete Printing, Life Cycle Assessment, Cradle-to-grave, Digital Fabrication, Load Bearing Structure, Carbon Efficiency

Posted Date: January 21st, 2022

DOI: https://doi.org/10.21203/rs.3.rs-1253072/v1

License: (c) (1) This work is licensed under a Creative Commons Attribution 4.0 International License.

Read Full License 


\title{
Lightweight 3D Printed Concrete Beams Show an Environmental Promise: A Cradle-to-Grave Comparative Life Cycle Assessment
}

\author{
Styrmir Gislason $^{\mathrm{a}}$, Simon Bruhn ${ }^{\mathrm{a}}$, Luca Breseghello ${ }^{\mathrm{b}}$, Burak Sen ${ }^{\mathrm{a}}$, Gang Liu ${ }^{\mathrm{a}}$, Roberto Naboni ${ }^{\mathrm{b}}$ *
}

${ }^{\text {a }}$ SDU Life Cycle Engineering, Department of Green Technology (IGT), Faculty of Engineering, University of Southern Denmark, Odense, Denmark

${ }^{\mathrm{b}}$ CREATE - Section for Civil and Architectural Engineering, University of Southern Denmark, Odense, Denmark

*Corresponding author

ron@iti.sdu.dk

\section{ARTICLE INFO}

\section{Keywords:}

3D Concrete Printing

Life Cycle Assessment

Cradle-to-grave

Digital Fabrication

Load Bearing Structure

Carbon Efficiency

\section{ABSTRACT}

Despite the increasing interest in 3D Concrete Printing (3DCP) in construction, limited research has quantitatively investigated the environmental impact that 3DCP brings. The existing Life Cycle Assessment (LCA) studies in the field can be criticized for a lack of clearly defined functional units of comparison, especially considering load-bearing structures. This paper investigates the potential environmental benefits of 3DCP over conventional concrete construction in a case study of structural beams based on a cradle-to-grave comparative LCA. Unlike in the existing LCA studies on $3 \mathrm{DCP}$, this paper employs a carbonation model to account for the potential carbon offsetting from the use-stage of 3DP concrete, which showed to be significant for the results. The assessment includes three-beam designs, each analyzed for both prefabrication and on-site construction scenarios. While 3DCP generally has a higher environmental impact due to the larger quantity of cement employed in the process, the reduction of materials through shape and infill optimization results as valid design principles to reduce emissions. Results show that, while standard designed 3DCP beams perform worse than their equivalent cast beams, lightweight designs for printed beams are promising in terms of reducing the environmental impacts from construction. The paper draws recommendations for future research on material development, e.g. integration of larger aggregates and low-clinker cement, and carbonation-efficient 3DCP design of load-bearing structures, e.g. considering the environmental benefits of recarbonation in the design optimization process.

\section{Introduction}

\subsection{Global Environmental Impact of Concrete Construction}

The construction industry is estimated to be responsible for $33 \%$ of greenhouse gases (GHG) emissions and $40 \%$ of the global resource use and waste generation (Eberhardt et al. 2020). On average, $7 \%$ of global anthropogenic CO2 emissions are attributed to construction using concrete (IEA 2018; Miller et al. 2016). The global production of cement, the fundamental constituent of 
concrete, has been steadily increasing and was estimated to be $4.1 \mathrm{Gt}$ in 2020 (Hatfield 2021) with a projection above 4.7 Gt in 2050 (IEA 2018). The majority (77\%) of the GHGs caused by cement production is carbon dioxide $\left(\mathrm{CO}_{2}\right)$ emissions attributable to the clinker production, which requires heating at around 1400 degrees Celsius. This results in high Embodied Energy (EE) that ranges from 0.6 to $2.0 \mathrm{MJ} / \mathrm{kg}$ in the produced concrete (Barcelo et al. 2014).

Current EU policies target a $40 \% \mathrm{CO}_{2}$ emissions reduction by 2030 compared to the 1990 -level, with a suggested proposal of raising the target to 55\% (European Commission 2021). The IEA and key cement companies created a shared objective to target a 20-25\% reduction in carbon emissions by 2030 (IEA 2020). This points towards a growing interest in sustainable alternatives to conventional construction methods and materials.

Together with the development of more sustainable materials, an increasing body of research is revolving around digital and automation strategies for sustainable design and manufacturing technologies. The optimization of structural design has been reported to result in $18 \%$ to $24 \%$ reductions in cost and carbon emissions in concrete structures (Gan et al. 2019). The increased fabrication freedom and automation potential unfolded by digital fabrication techniques can lead to a further reduction in GHG emissions and costs (Agustí-Juan et al. 2017).

Among emerging automation technologies for sustainable construction, Additive Manufacturing (AM) occupies a fundamental role, enabling strategic material placing (Naboni et al. 2019). Research in AM-enhanced concrete construction is mainly distinguished between (i) indirect applications for Additive Formwork Manufacturing (AFM) to produce elements of variable complexity (Naboni and Breseghello 2019, Naboni and Breseghello 2020) and structural elements (Burger et al. 2020); and (ii) direct 3D printing of construction elements (Buswell et al. 2018). Within these application fields, 3D Concrete Printing (3DCP) is the main AM technique that has attracted the interest of both research (Labonotte et al. 2016, Perrot 2019, Buswell et al. 2020) and innovative practice (COBOD 2021, XTreeE 2021, CyBe 2021, Icon 2021, Winsun 2021).

In this framework, this paper focuses on the use of Life Cycle Assessment (LCA) for critical analysis of the environmental impacts of 3DCP for the manufacturing of reinforced concrete horizontal structures (Fig. 1), which accounts for almost $43 \%$ of the concrete use in a reinforced concrete construction (Cho et al. 2004). The aim is evaluating the readiness of the current state-oftechnology and state-of-design in 3DCP as a valuable solution to reducing GHG emissions. 


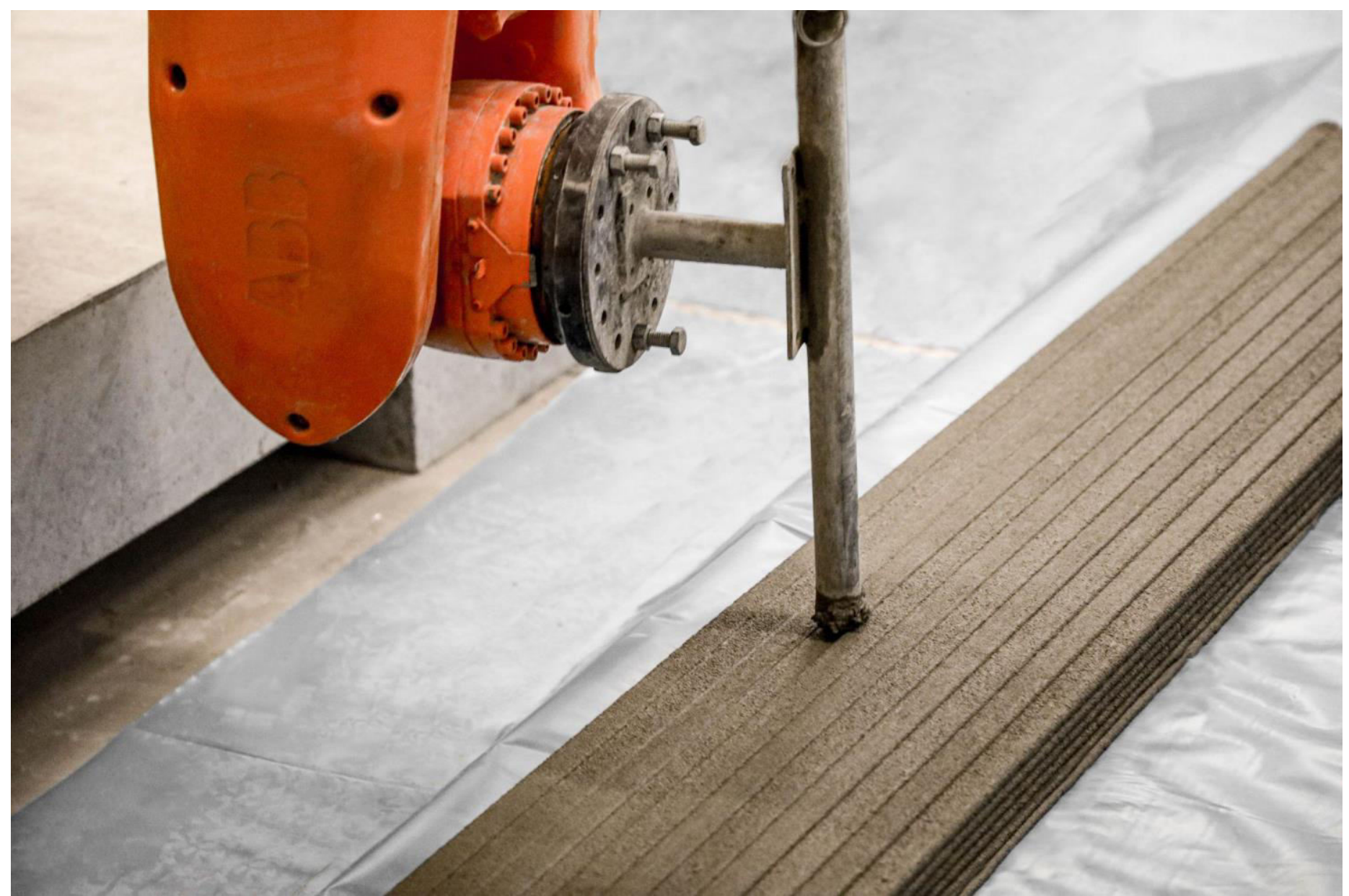

Fig. 1. Robotic 3DCP process of a full volume benchmark beam at the CREATE Lab (SDU)

\subsection{D Concrete Printing for Structural Applications}

3DCP is an AM technique where semifluid cement mortar is deposited in subsequent layers following a computer-generated path to creating a solid structure. To date, most research and industry projects employ mortar mixes with very fine aggregates and accelerating and plasticizing admixtures that are continuously extruded through a nozzle controlled by an industrial robotic arm or gantry system (Bos et al. 2016). The key benefits of this technology are that the material can be programmatically placed only where needed, and that no formwork is in principle required, increasing the material efficiency and the design freedom with reduced costs (Allwood et al. 2011, Mani et al. 2014). 3DCP enables the adoption of complex structures obtainable from structural optimization and functional hybridization (de Schutter et al. 2018). The reduction of concrete material usage through structural optimization as well as the reduction of auxiliary operations promise a large environmental impact in the construction industry (Chandra Paul et al. 2018; Vantyghem et al. 2020).

Despite the growing number of research studies and early applications, the full adoption of 3DCP in civil uses is still limited due to the infancy of the technique. Vertical elements, i.e. walls and columns, are the structural typology where 3DCP is most often employed in the industry, and particularly, for on-site applications, but also widely explored in research with a focus on aesthetics 
(Anton et al. 2020) and structural (Suiker et al. 2018) possibilities. Short span post-tensioned pedestrian bridges (Salet et al. 2018) have been tested and built, demonstrating advantages in customization and material savings (Vantyghem et al. 2020). Research was carried out on prefab beam elements, with explorations on reinforcement integration strategies (Gebhard et al. 2021) and code compliance (Mesnil et al. 2020), and material saving. However, challenges in modeling the anisotropic mechanical behavior (Panda et al. 2017), in the simulation of printed structures, the inherent limitations of the layered manufacturing process, and the difficulties in integrating reinforcements, currently bound 3DCP to often simplistic solutions.

To further enhance the effectiveness of 3DCP as an environmentally sustainable construction practice, it is crucial to jointly investigate the development of structural design models and the study of their environmental implications. In this light, this work introduces a novel method for designing and manufacturing lightweight load-bearing horizontal structures with 3DCP and analyzes its potential environmental impacts through a cradle-to-grave life cycle assessment.

\subsection{Life Cycle Assessment of 3DCP}

The current research focus regarding emissions in concrete construction is on GHGs. Multiple LCAs for cement production reports high variance in the amount of GHG emissions, in the range of approximately 500 to $950 \mathrm{~kg}$ of $\mathrm{CO}_{2} \mathrm{eq}$ per ton of cement produced (Lei et al. 2011).

In the literature are found three comparative LCAs on 3DCP of relevance for this study. Weng et al. (2020) compared prefabricated bathroom units and reported lower environmental impacts associated with 3DCP due to the assumptions formulated about the reuse of formworks used in their analysis. Their sensitivity analysis shows that a breakeven of emissions is reached at around 25 reuses, which results in traditional manufacturing being most beneficial when considering extensive reuse of the formworks. Alhumayani et al. (2020) carried out a comparative LCA study where unreinforced 3DCP walls are compared to reinforced cast-concrete walls. Comparing it to cast concrete, the study reports $27.2 \%$ higher climate change potential for $3 \mathrm{DCP}$, indicating relatively higher impacts from GHG emissions for 3DCP, while all other impact categories resulted lower. Mohammad et al. (2020) compared a conventional reinforced concrete wall to a 3DCP reinforced wall, as well as to two different unreinforced 3DCP load-bearing walls of $1 \mathrm{~m}^{2}$. The study presents significantly lower impacts from the unreinforced walls. The reinforced walls show a higher climate change potential for the 3DCP, but a lower potential in terms of acidification, eutrophication, and smog formation.

These valuable studies lack the definition of a clearly identified Functional Unit (FU), arguably a significant factor that could affect the results of an LCA (Panesar et al. 2017). Furthermore, the literature review highlighted limitations in their system definition, i.e. adopting a cradle-to-gate system boundary, ending at the manufacturing stage. Furthermore, to the best of our 
knowledge, no existing LCA has yet focused on evaluating the environmental impact of horizontal load-bearing structures realized with 3DCP.

The presented work aims at addressing the above-mentioned gaps and answering the following three research questions:

(1) What are the main parameters that influence the environmental impacts of the 3DCP technology, and which of these are associated with the most uncertainty?

(2) What is the magnitude of the environmental impact of 3DCP beams compared to traditional cast-concrete beams in a cradle-to-grave comparison?

(3) Given the modeling assumptions considered in this study, how do prefabrication and on-site manufacturing compare for both 3DCP and cast beams?

\section{Materials and Methods}

\subsection{Experimental Studies on 3DCP at SDU CREATE}

The CREATE Group at the University of Southern Denmark is currently investigating novel design and manufacturing strategies that take advantage of 3DCP to fabricate high-resolution lightweight structures in concrete. Preliminary works consisted in the development of a fabrication setup, of a specific material mix and its characterization (Joergensen et al. 2021), and a digital simulation and visualization tool to predict the material behavior of the 3DCP process and its outcome (Breseghello and Naboni 2021a) These tools have been exploited in a design and fabrication experiment where the printing path and robot code are programmatically manipulated (Breseghello and Naboni 2021b).

The design scenario of the presented paper is that of structural reinforced concrete beams for civil uses to be placed below a slab, characterized by a similar boundary volume of $3.00 \times 0.30 \times 0.16 \mathrm{~m}$, but differing in their internal material layout. The outcomes are a series of elements with different levels of porosity, and consequently volume of material and weight (Fig. 2, left). For comparability with conventional beams, the shape and the section of the beams are set as a standard rectangular, and any possible functional integration, e.g. with the slab or with installation conduits, is avoided. Structural optimization and smart toolpath planning were integrated into the workflow to optimize the design and fabrication processes, as well as the structural performance of the manufactured beams. 

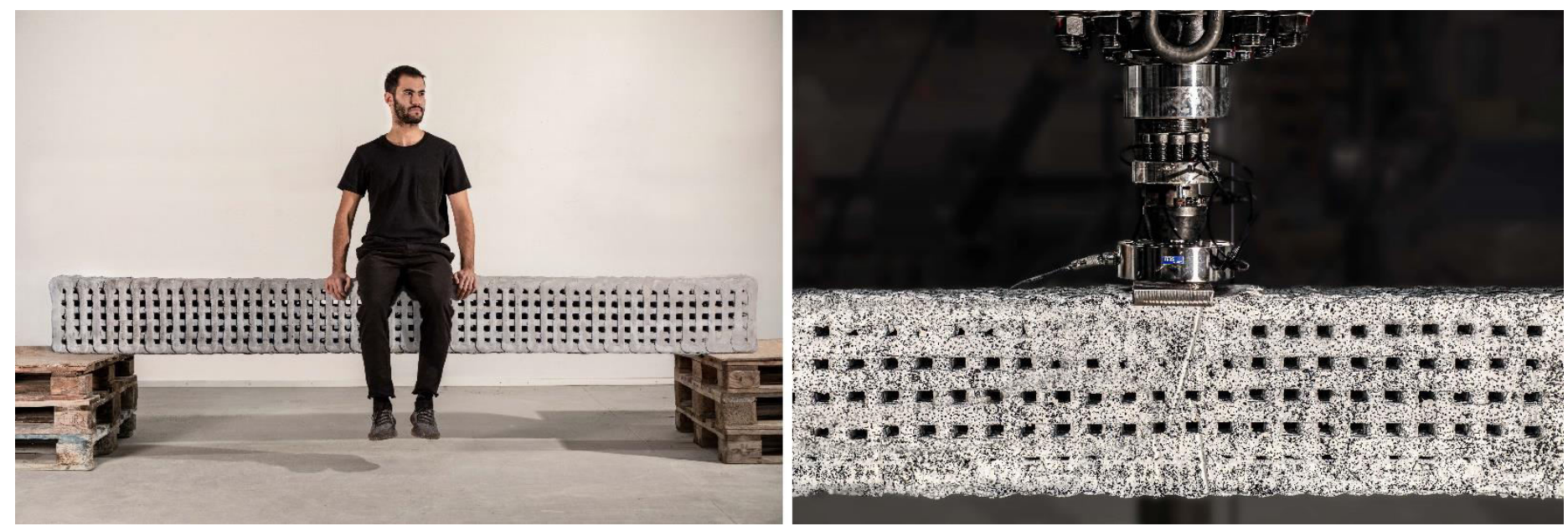

Fig. 2. Porous beam prototype, i.e. Grid 3DCP Beam (left) and three-point bending structural testing of the 3DCP reinforced concrete lightweight beams (right), from the 3DLightBeam project by CREATE (SDU).

The printed elements were designed as simply supported beams of $3 \mathrm{~m}$, i.e. with a vertical point load in their middle at $1.5 \mathrm{~m}$, and characterized by a span of $2.76 \mathrm{~m}$, with supports at $0.12 \mathrm{~m}$ from each longitudinal edge. The beams were subsequently tested structurally via a three-point bending test (Fig. 3, right). The results from the fabrication and the subsequent testing proved the viability of the approach in terms of strength and reduced material use.

\subsection{LCA Goal and Scope}

The LCA presented in this study has been conducted based on the ILCD handbook and following the international standards such as ISO14040, ISO14044, and EN15804 (i.e. a standard on the sustainability of construction works) to ensure the standardization and replicability of the results. All modeling assumptions are based on the relevant scientific literature, empirical data, and expert testimony from industry and academia (Table S.1). The EC-JRC impact assessment method, also known as EF 3.0, has been adopted as recommended by the 15804 standards. SimaPro 9.1 and EcoInvent 3.6 cut-off databases (Ecoinvent, 2020) were utilized for the inventory modeling and impact assessment. Hotspot and sensitivity analyses have been carried out to discover the main sources of emissions, and understand which parameters would be subject to a high degree of variance in the results.

The goal of the LCA conducted in this study is to unveil the potential life cycle environmental impacts of two load-bearing beam designs, i.e. a Solid 3DCP Beam (B1) (Fig. 3a) and a Grid Beam (B2) with about 25\% material reduction characterized by an orthogonal grid layout (Fig. 3b). Both the designs are developed and printed by the CREATE Group at the University of Southern Denmark (SDU). Taking from the results of the structural tests performed on the printed specimens, the Functional Unit (FU) has been formulated as a function of failure in three-point bending for two beams, and it is given as the following: 
Beams of $3 \mathrm{~m}$ length with a span of $2.76 \mathrm{~m}$ in a simply supported beam setup, tested in three-point bending with a failure of $43.7 \mathrm{kN}$ and an estimated lifetime of 50 years.

The FU has been set to equal the load-bearing capacity achieved from the test results of (B1). The strength of $43.7 \mathrm{kN}$ is the average failure load of the conducted tests. The chosen data for comparison is Ultimate Limit State (ULS). Based on Eurocode2, an alternative FU could be based on the Service Limit State (SLS), i.e. the load at maximum admissible deflection of the beam, which for this used span is equal to about $11 \mathrm{~mm}$ (Dansk Standard, 2008). However, given the proportional outputs of the two calculations, the former has been selected.

A third theoretical Cast Beam (B3), representative of a conventional concrete structure, was designed using standard engineering procedures as a $3 \mathrm{~m}$ element with the same functional characteristics described above (Fig. 3c). It was designed considering the same rebar arrangement as $B 1$ with a $40 \mathrm{MPa}$ concrete mixture. The calculations for $B 3$ are based on the work of Wight and Macgregor (2011) and verified by the software Polybeam (PolyStruc 2021). 


\section{B1 | SOLID 3DCP}

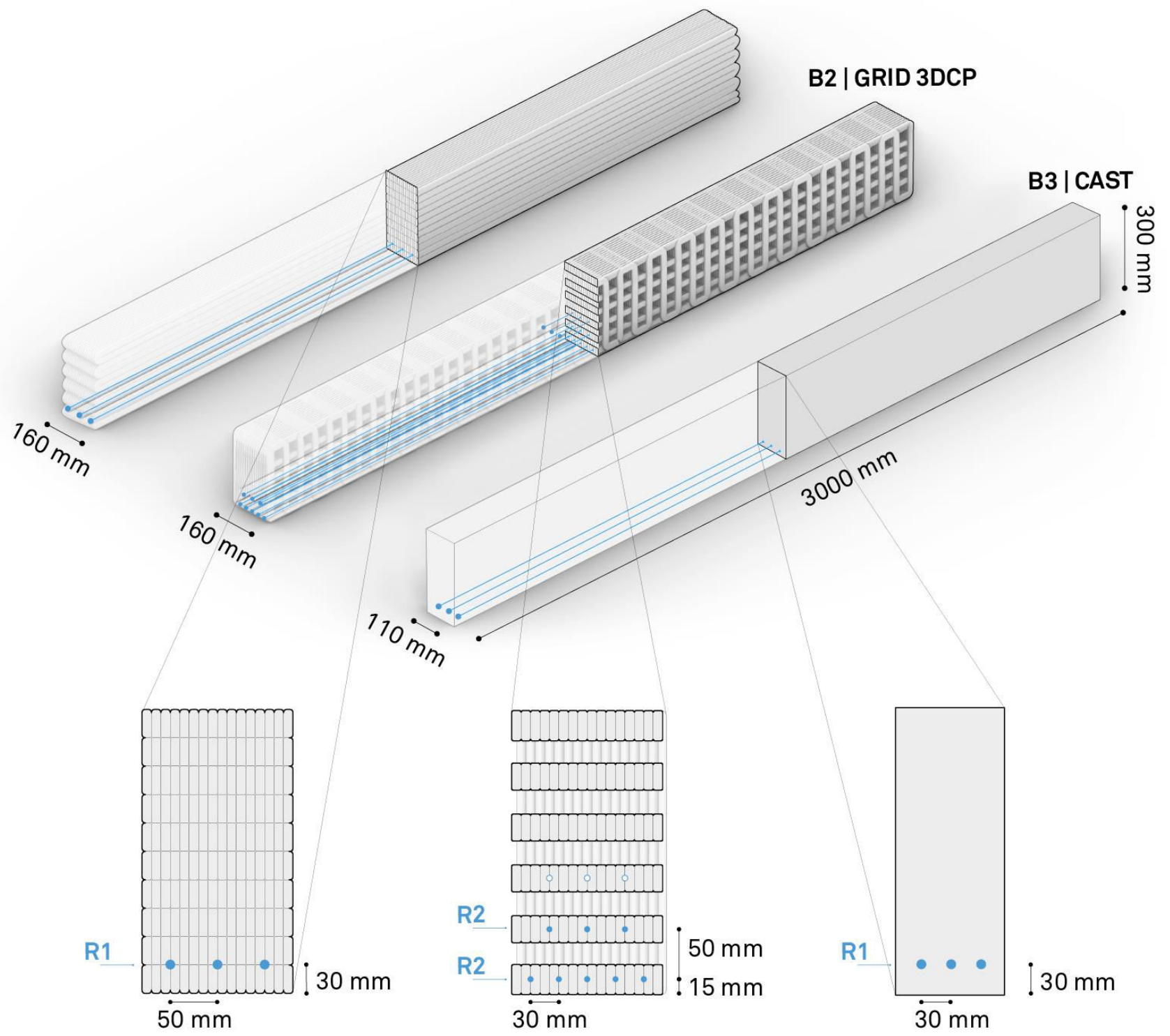

Fig. 3. Axonometric and section view of the three studied beams: (B1) Solid 3DCP beam; (B2) Grid 3DCP beam; (B3) Cast beam

Considering the defined FU, a reference flow of 0.87 for the $B 2$ and of 1 for $B 3$ are applied to provide the same load-bearing capacity owing to their higher performance. The LCA considers beams produced at the current time and disposed of 50 years in the future. The geographical scope is limited to Denmark. No multifunctionality was identified in the foreground system. The compared systems are summarized in Table S.2.

The system boundary includes all the life cycle tiers of the studied beams, i.e. material extraction, manufacturing, use, transportation, and disposal (Fig. 4). Additionally, the system boundary has been extended to include the life cycle environmental impacts of essential manufacturing equipment (i.e., the robotic arm and pump) to account for the effect of its reuse, accurately. The entire lifecycle of the manufacturing equipment has been assumed to be a part of the production process, which means the disposal of the manufacturing equipment will be attributable to the manufacturing stage when considering a hotspot analysis. 


\section{SYSTEM BOUNDARY}

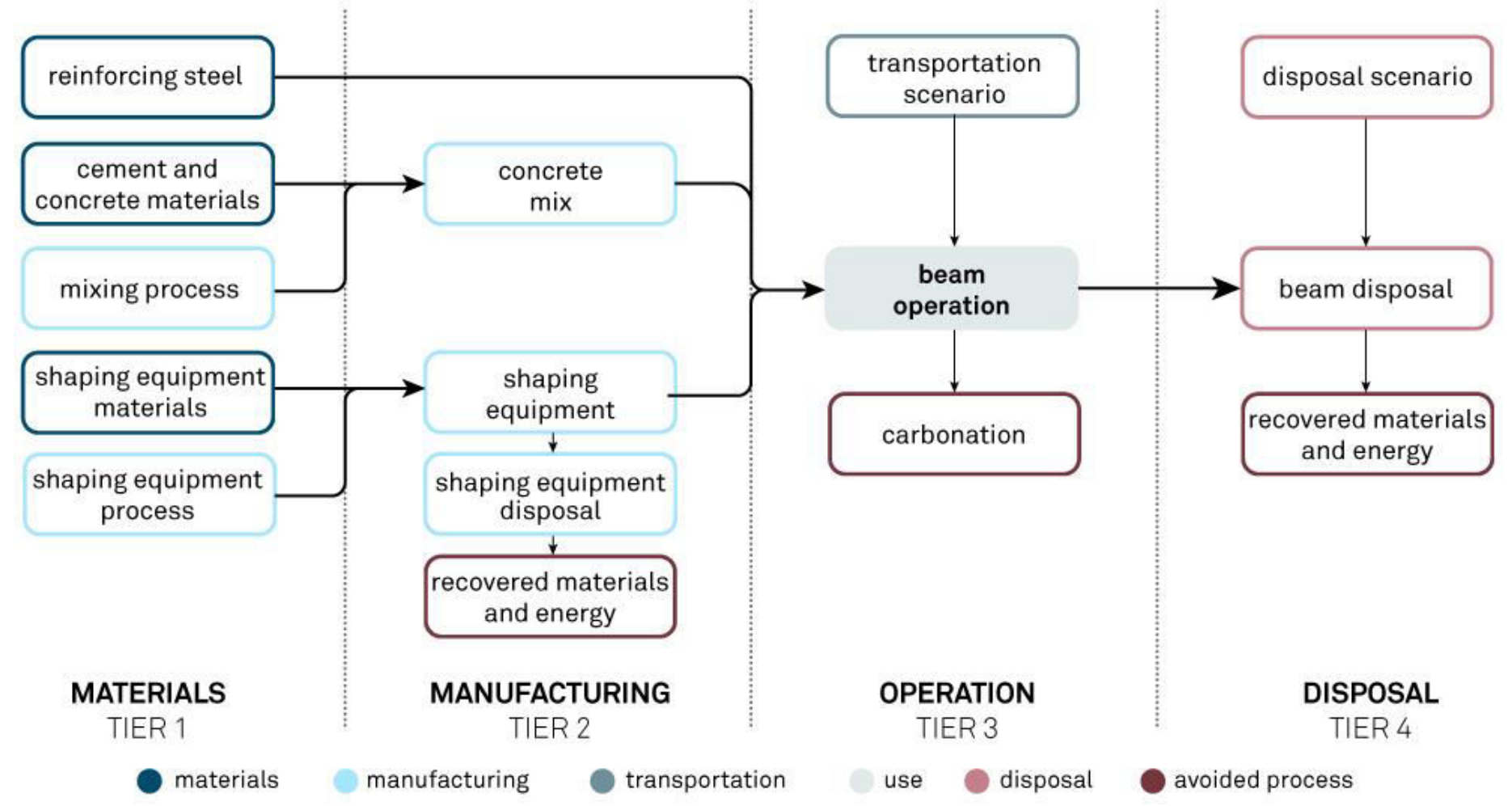

Fig. 4. The system boundary of the LCA model

In compliance with EN15804, the LCA reports the impact categories as seen in Table S.3 at characterized midpoints. Furthermore, an aggregated single score will be reported for a more straightforward evaluation of all impact categories.

\subsection{Life Cycle Inventory}

\subsubsection{Materials}

The composite nature of reinforced concrete consists of different components: the concrete mix, i.e. aggregates (gravel and sand) bound together with a cement matrix and mixed with water, and steel rebars. Reinforcing steel for concrete is generally of a low grade and not subject to variability, resulting in a uniformity of the material profiles for the 3DCP and cast-concrete beams. Compared to casting processes, 3DCP currently requires a concrete mix with smaller aggregates to be pumped through the system, and accelerator admixtures for faster hardening rates that allow withstanding the load of the subsequent layers.

$B 3$ is considered to be produced with a $40 \mathrm{MPa}$ strength concrete mix, and all the related data were obtained from the EcoInvent 3.6 database. To better represent the high variability of the concrete mixes for 3DCP found in the literature, the process $3 D C P$ mixture presented in Table S.4 was defined as the average between the mixtures used at SDU and two other mixtures from (Anell 2015; Nerella and Mechtcherine 2019). For the modeling of the 3DCP concrete mixture, the specific unit process, Concrete 45MPa (RoW) was obtained from the EcoInvent database and modified to represent the averages previously mentioned. 


\subsubsection{Manufacturing}

Three manufacturing systems were identified for the following processes: i) a robotic 3DCP cell, consisting of a medium payload 6-axis industrial robot and a concrete pump; ii) a wooden formwork for on-site cast-concrete fabrication, and iii) a steel formwork for cast-concrete prefabrication (Table 1). Adequate formwork materials and amounts were estimated based on an interview with Spaencom A/S, a Danish concrete prefab elements manufacturer. The reuse of the formwork was selected similarly and included in the sensitivity analysis.

The robotic cell was modeled based on the current 3DCP cell at the SDU CREATE Lab, which includes a 6-axis ABB IRB 6650S robotic arm, and a PFT ZP 3 XL conveying pump (Fig. 5). The technical data available from the manufacturers were utilized along with the estimates of the parts and processes required for the manufacturing of the robotic cell. The amount of energy necessary for operating the robotic arm was calculated utilizing the Pareto principle (Slack et al. 2013), which assumes that the robotic arm is used at $80 \%$ of its maximum capacity for $20 \%$ of the time and operated at $20 \%$ of its full capacity for the remaining $80 \%$ of the time. It was also assumed that $75 \%$ of the pump and the robotic arm are repurposed at the end of life.

Table 1. Modeling assumptions for manufacturing equipment

\begin{tabular}{|c|c|c|c|c|}
\hline & Pump (PFT ZP3XXL) & Robot (ABB IRB6650S) & On-site Formwork & Prefabrication Formwork \\
\hline Total weight & $240 \mathrm{~kg}$ & $2250 \mathrm{~kg}$ & $33.2 \mathrm{~kg}$ & $200 \mathrm{~kg}$ \\
\hline $\begin{array}{l}\text { Materials \& } \\
\text { processes }\end{array}$ & $\begin{array}{l}55 \mathrm{~kg} \text { electric motor } \\
51 \mathrm{~kg} \text { frequency inverter } \\
114 \mathrm{~kg} \text { low-alloy steel } \\
114 \mathrm{~kg} \text { Metalworking, } \\
20 \mathrm{~kg} \text { ABS plastic } \\
20 \mathrm{~kg} \text { injection molding }\end{array}$ & $\begin{array}{l}50 \mathrm{~kg} \text { e-motors } \\
30 \mathrm{~kg} \text { cables } \\
20 \mathrm{~kg} \text { electronics } \mathrm{PCB} \\
2100 \mathrm{~kg} \text { steel } \\
1600 \mathrm{~kg} \text { casting } \\
10 \mathrm{~kg} \text { steel machining } \\
500 \mathrm{~kg} \text { die stamping } \\
20 \mathrm{~m} \text { welding }\end{array}$ & $\begin{array}{l}33.2 \mathrm{~kg} \text { Plywood } \\
0.332 \mathrm{~h} \text { power sawing }\end{array}$ & $\begin{array}{l}\text { 200kg Stainless Steel } \\
\text { 200kg } \quad \text { Metalworking } \\
\text { processes }\end{array}$ \\
\hline Operation & $2.4 \mathrm{kWh}$ & $0.768 \mathrm{kWh}$ & None & None \\
\hline Reuse & 35.000 hours & 35.000 hours & 5 castings & 2000 castings \\
\hline Disposal & $75 \%$ component reuse & $75 \%$ component reuse & Incineration & Scrap steel \\
\hline
\end{tabular}




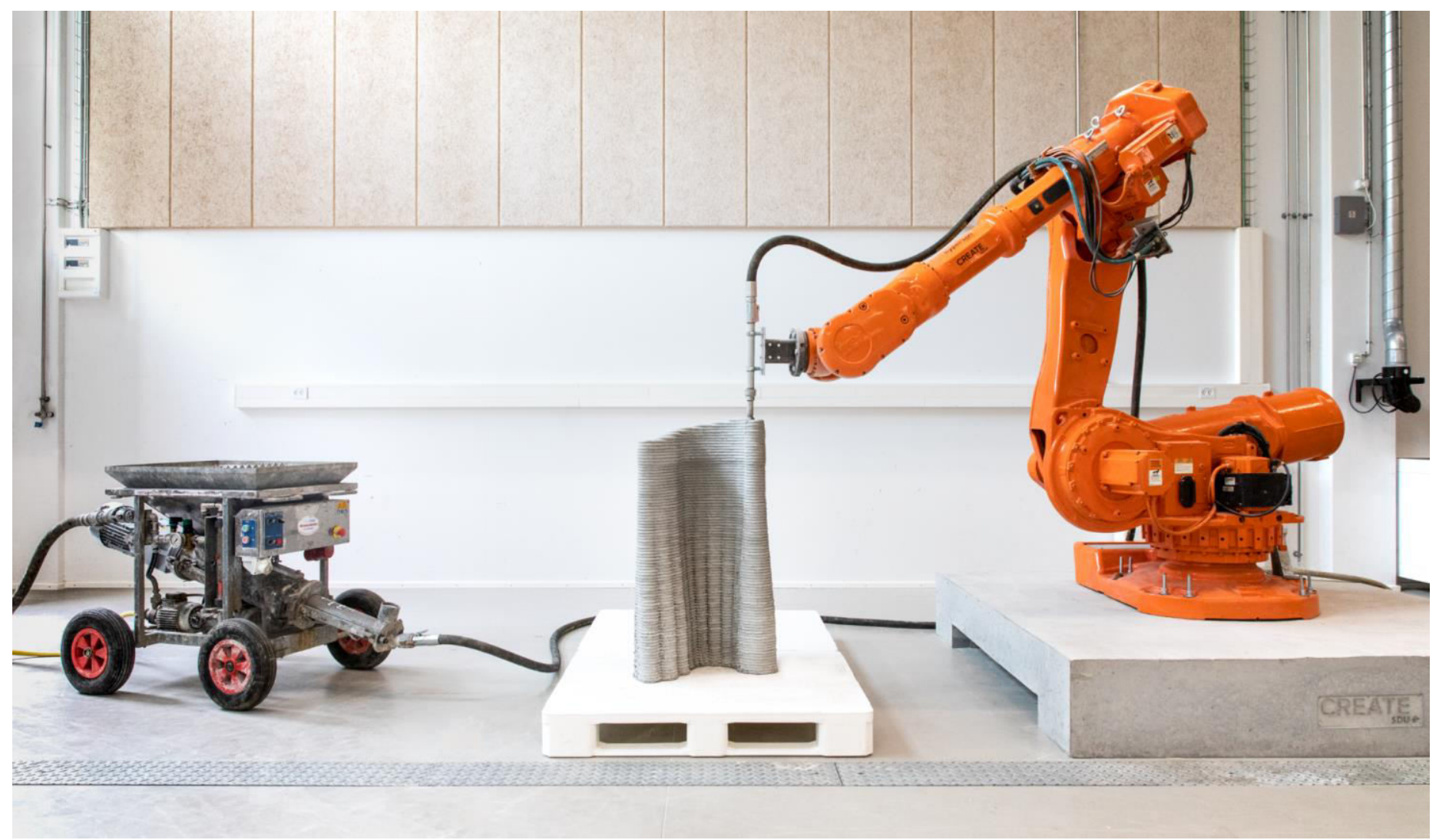

Fig. 5. 3DCP fabrication setup at the CREATE Lab

\subsubsection{Transport}

Market mix processes were utilized for the assumption of transportation of raw materials to a specific location in Denmark. In contrast, two different transportation scenarios were identified for the on-site and prefab units. The transported weight consists either of raw materials and manufacturing equipment for on-site construction or of the manufactured beam in the prefab production system. The prefabrication assumes that the final product is transported to the construction site from a single facility in Denmark that is 250 $\mathrm{km}$ far from the site. The on-site scenario assumes that more facilities are present, with a $50 \mathrm{~km}$ distance to the construction site, and a $50 \mathrm{~km}$ return of the manufacturing equipment (Fig. 6).
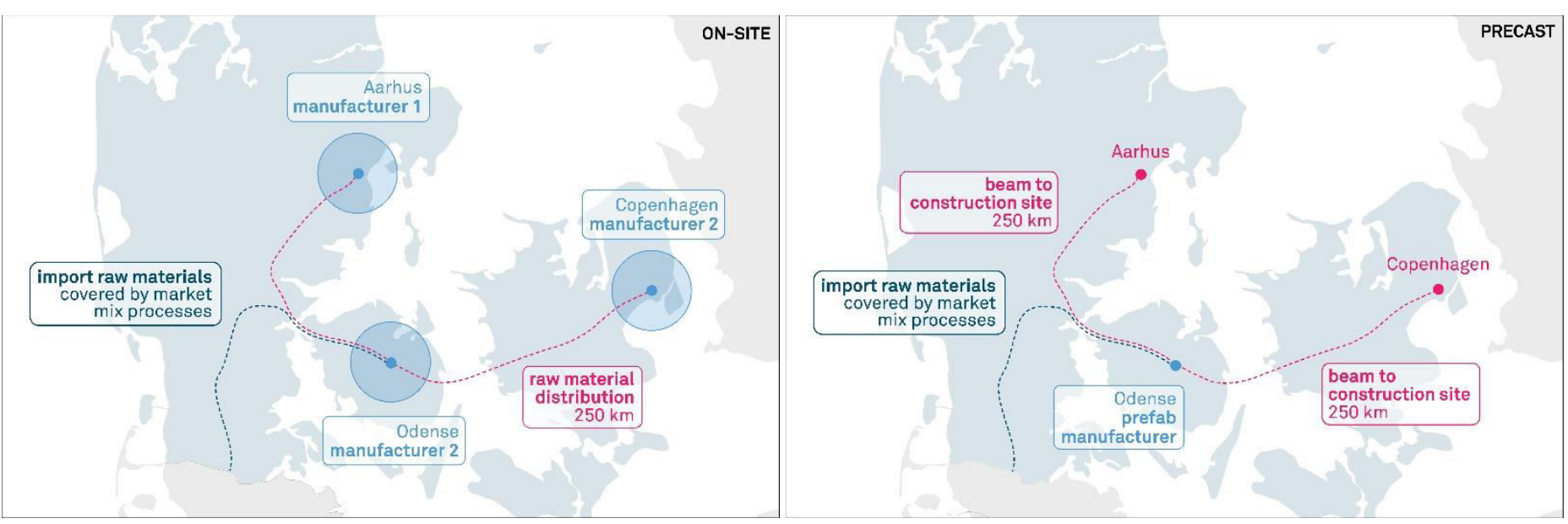
Fig. 6. Transportation flows for the on-site (above) and precast (below) production processes. Copenhagen, Odense, and Aarhus are considered for this study as the three major Danish cities, and strategically located in the national territory.

\subsubsection{Use Stage}

Given its potential to offset $\mathrm{CO}_{2}$ emissions from concrete production (Xi et al. 2016, Cao et al. 2020), concrete recarbonation has been included in the assessment. The modeling of recarbonation can be complex as it relies on multiple environmental, physical, and material parameters (Venkat Rao and Meena 2017). The Lagerblad model was employed for its simplicity of application, introducing constants for environmental conditions and concrete mixtures (Lagerblad 2005). The following steps were accordingly implemented:

1. Assess the depth of recarbonation based on the parameters presented:

$$
d=k * \sqrt{t}
$$

2. Assess the volume $\left(\mathrm{m}^{3}\right)$ of the concrete based on the exposed surface area:

$$
\text { m3 carbonated }=\sum A * d
$$

3. Assess the $\mathrm{CO}_{2}$ amount based on the carbonized volume based on the material profile:

$$
\mathrm{kgCO}_{2} \text { per } \mathrm{m}^{3}=0.75 * \mathrm{C} * \mathrm{CaO} * \frac{\mathrm{MCO}_{2}}{\mathrm{MCaO}}\left(\frac{\mathrm{kg}}{\mathrm{m}^{3}}\right)
$$

4. Assess the total $\mathrm{kg}$ of $\mathrm{CO}_{2}$ uptake of the concrete element by multiplying results from steps 2 and 3

$$
m 3 \text { carbonated } * \mathrm{kgCO}_{2} \text { per } \mathrm{m}^{3}=\mathrm{kgCO}_{2} \text { carbonated }
$$

Where:

$d$ is the depth of recarbonation, $k$ is a constant for environmental effects ( 3.5 for this study), $t$ is years of recarbonation (50 for this study), $A$ is the area in $\mathrm{m}^{2}$ exposed to air, $\mathrm{C}$ is the mass of portland cement clinker per $\mathrm{m} 3, \mathrm{CaO}$ is the amount of $\mathrm{CaO}$ in cement (weight \%), $\mathrm{Mco} 2 \mathrm{is}$ the molar mass of $\mathrm{CO}_{2}, \mathrm{McaO}$ is the molar mass of $\mathrm{CaO}$ 


\subsubsection{Disposal}

Currently, $89 \%$ of concrete is recycled as road filling in Denmark, while the remaining $11 \%$ is estimated to be landfilled (EEA 2020). The disposal is assumed to occur 50 years in the future, where improvements are to be expected. Hence, it was assumed that while no landfilling occurs (Zhang et al. 2019), 50\% of concrete waste is processed for high-grade recycling for aggregates in new concrete, and the remaining 50\% is to be used for low-grade recycling for road filling (Pedersen and Ottosen 2019).

\subsection{Sensitivity Analysis}

A sensitivity analysis was conducted on the parameters identified as uncertain in values or likely subject to variation during the inventory modeling. The parameters were grouped into six categories, resulting in six uncertainty assessments considering the bestand worst-case estimates of parameter values (Table 2). The six cases identified were the recarbonation amount, clinker content, transportation, reuse of manufacturing equipment, recycling efficiency, and energy use of 3DCP cells. The results were compared for midpoint categories for the varying scenarios.

Table 2. Uncertain parameter values were grouped into categories, and sensitivity was assessed in worst and best cases compared to the best estimates of the inventory model. More information in S.5.
Worst-case
Realistic case (inventory model)
Best-case

\begin{tabular}{|c|c|c|c|}
\hline $\begin{array}{l}\text { Category 1: recarbonation of } \\
\text { concrete }\end{array}$ & $\begin{array}{l}\text { Correction factors lowest } \\
\text { values }\end{array}$ & Best estimate of correction factors & $\begin{array}{l}\text { Correction factors highest } \\
\text { values }\end{array}$ \\
\hline Category 2: Clinker content & $\begin{array}{l}\text { Cast: } 95 \% \\
\text { 3DCP: } 95 \%\end{array}$ & $\begin{array}{l}\text { Cast: } 62 \% \\
\text { 3DCP: } 95 \%\end{array}$ & $\begin{array}{l}\text { Cast: } 62 \% \\
\text { 3DCP: } 62 \%\end{array}$ \\
\hline \multirow{2}{*}{$\begin{array}{l}\text { Category } 3 \text { : Transportation distance } \\
\text { to the construction site }\end{array}$} & $250 \mathrm{~km}$ & $50 \mathrm{~km}$ & $10 \mathrm{~km}$ \\
\hline & $500 \mathrm{~km}$ & $250 \mathrm{~km}$ & $50 \mathrm{~km}$ \\
\hline \multirow{3}{*}{$\begin{array}{l}\text { Category 4: Reuse and lifetime of } \\
\text { manufacturing equipment }\end{array}$} & $1 *$ & 5 & 100 \\
\hline & $1000 * *$ & 2000 & 10000 \\
\hline & $10000 \mathrm{~h}^{* * *}$ & $35000 \mathrm{~h}$ & $100000 \mathrm{~h}$ \\
\hline \multirow{2}{*}{$\begin{array}{l}\text { Category } 5 \text { : Recycling (EoL) of } \\
\text { manufacturing equipment and } \\
\text { beams }\end{array}$} & $\begin{array}{l}89 \% \text { recycled to road filling } \\
11 \% \text { landfilled }\end{array}$ & $\begin{array}{l}50 \% \text { recycled to new concrete aggregate } \\
50 \% \text { recycled to road filling }\end{array}$ & $\begin{array}{l}100 \% \text { recycled to new concrete } \\
\text { aggregate }\end{array}$ \\
\hline & $25 \%$ & $75 \%$ & $100 \%$ \\
\hline $\begin{array}{l}\text { Category 6: Energy use of 3DCP } \\
\text { robot and pump }\end{array}$ & $2.4+7.5 \mathrm{kWh}$ & $0.768+2.4 \mathrm{kWh}$ & $0.48+1.5 \mathrm{kWh}$ \\
\hline
\end{tabular}

$*$ reuse of plywood formwork. ** reuse of steel formwork. *** lifetime of 3DCP equipment

\section{Results}

\subsection{Midpoint Impact Categories}

All the midpoint impact results, except for particulate matter, human toxicity (e.g., cancer), land use, and water use impact 
categories display higher impacts for the Solid 3DCP Beam (B1) (Fig. 7). The climate change potential of the B1 results is $300 \%$ higher than the Cast Beam (B3) and 180\% higher than the Grid 3DCP Beam (B2).

As presented in Table S.6, minimal differences were observed in the life cycle impacts of on-site 3DCP and prefab systems. However, significant differences in various impact categories were observed for the cast systems due to differences in manufacturing equipment. Overall, the Grid 3DCP Beam (B2) was found to have a $20 \%$ higher impact on average in the on-site and $40 \%$ in the prefab systems when compared to the corresponding cast concrete beams.

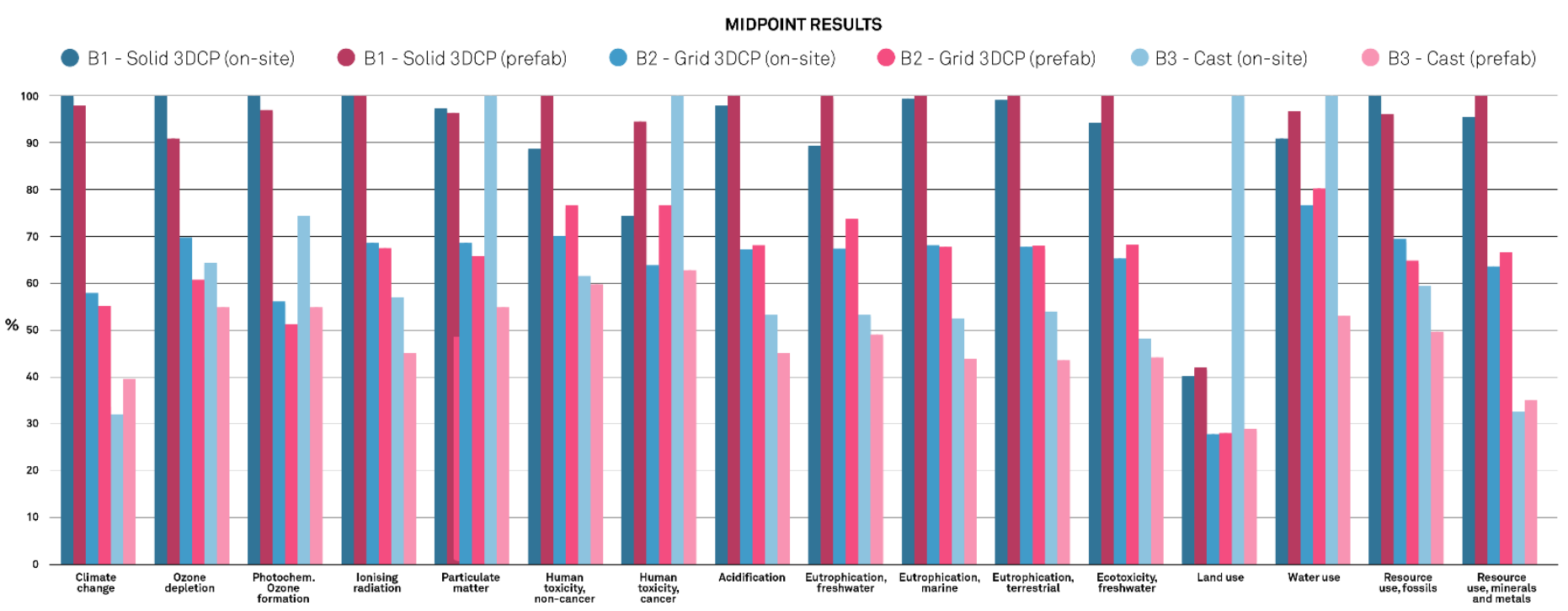

Fig. 7. Relative midpoint results of the compared systems

A single score comparison i.e. aggregated and weighed midpoints, is displayed in Fig. 8. Cast Beam (B3) is characterized by the lowest emissions 5.8 and $6.1 \mathrm{mPoints}$ for prefab and on-site respectively), followed by the Grid 3DCP Beams (B2) (9.2 and 9.3 $\mathrm{mPt}$ ), and finally the Solid 3DCP Beams (B1) with the highest single score (14.3 and $13.9 \mathrm{mPt})$. The results show most of the impacts are highly influenced by the three beam designs. The climate change potential and the fossil and mineral resource use contribute to most of the single score associated with the beams. 


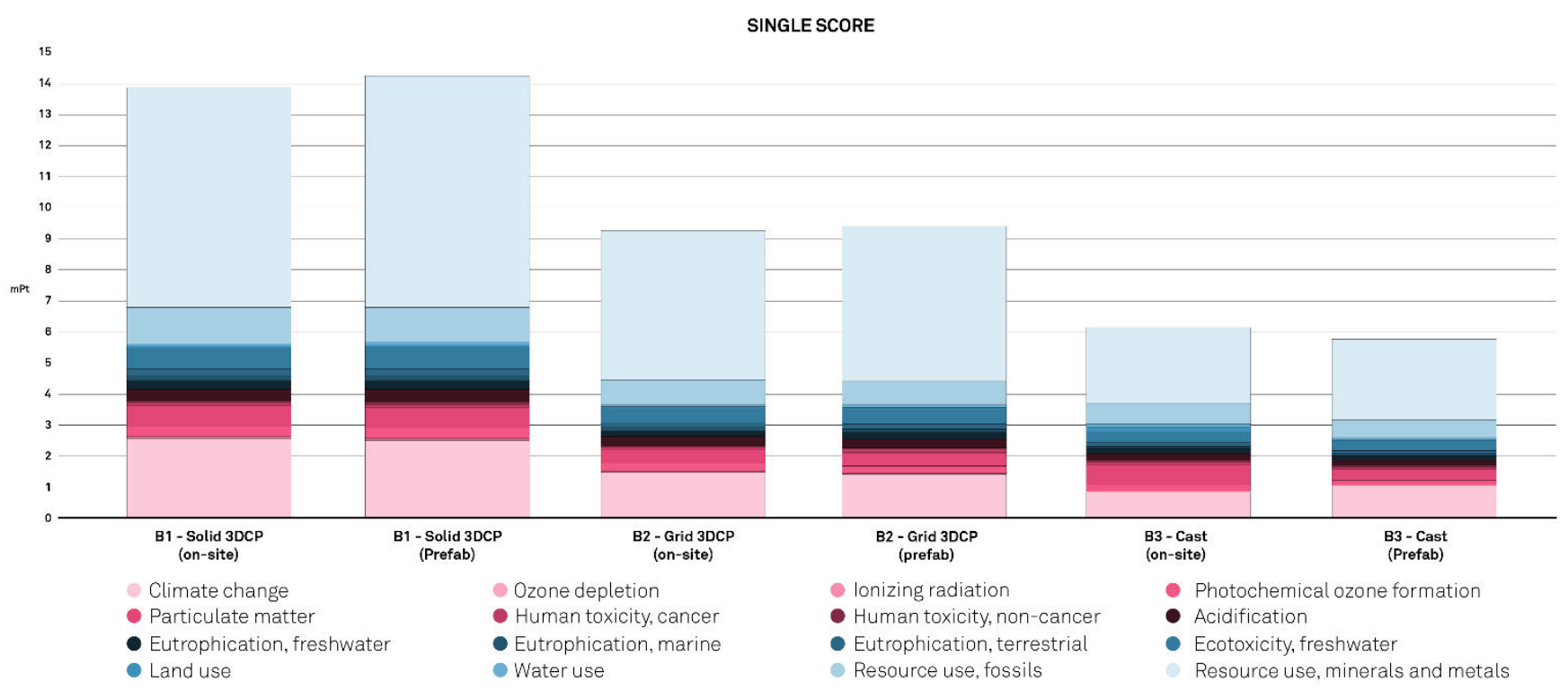

Fig. 8. Single score results, aggregation of the weighted midpoints.

\subsection{Hotspot analysis}

The hotspot analysis of the midpoint impact categories reveals that most of the impacts can be traced back to the material extraction stage (Fig. 9). Depending on the product system, the contribution of the manufacturing stage is generally minimal at around $2-15 \%$ of the total impact, except for the on-site cast-concrete system, which is due to the low reuse of plywood formwork that increased the contribution to the impact. Transportation contributes to a minimal amount of around $2-15 \%$, although generally higher values are observed for the 3DCP on-site systems due to transportation requirements for the 3DCP cell. The use stage results in an offset of approximately $10 \%$ for the Climate Change impact category due to recarbonation. The disposal is found to prevent impacts due to material substitution from recycling, resulting in negative impacts in various categories, the highest of which is the carcinogenic human toxicity which reduces approximately $40 \%$ of the total impact from the other stages (Fig. 9d). 

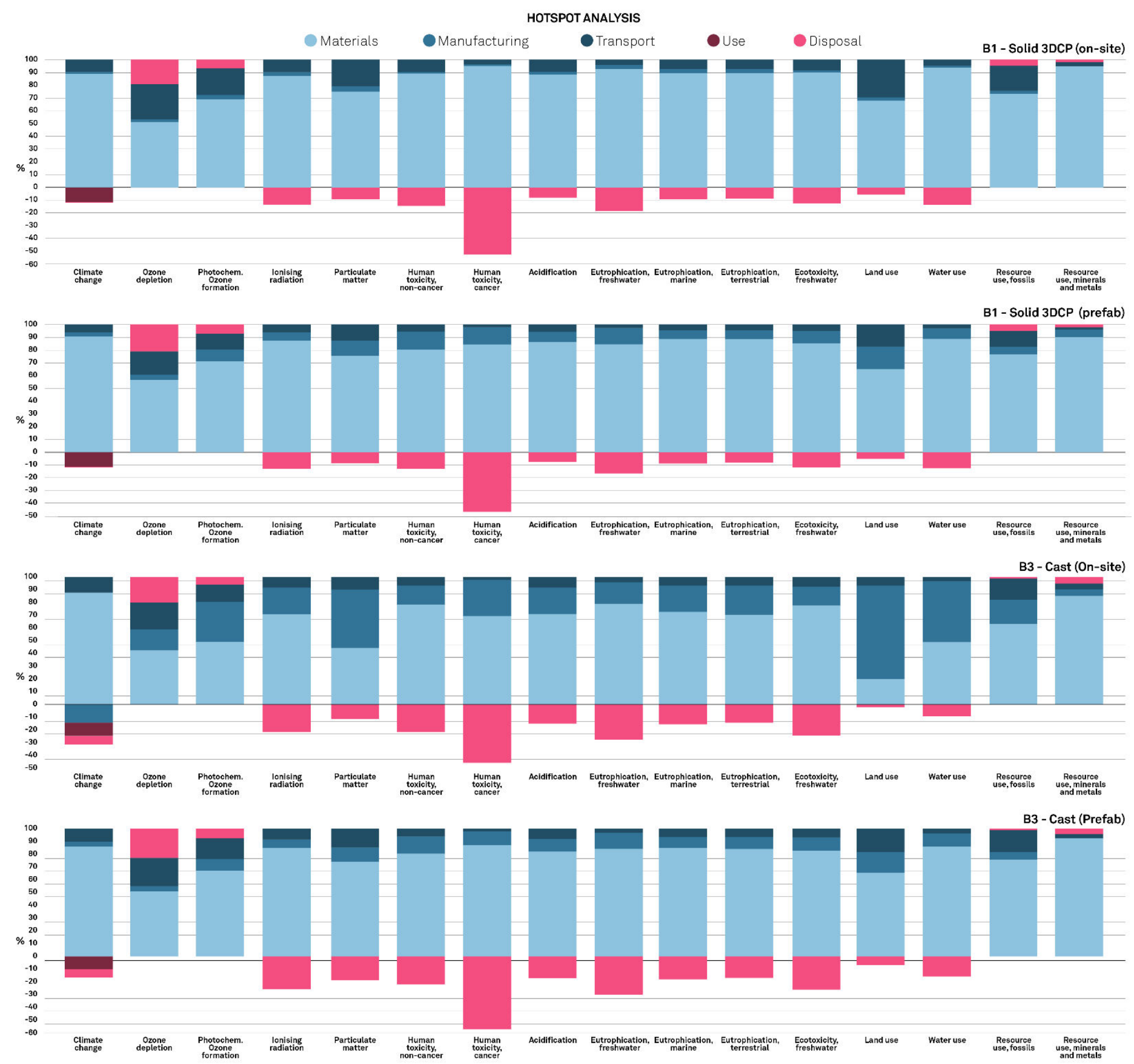

Fig. 9. Hotspot analysis of different product systems: B1 - Solid 3DCP on-site; B1 - Solid 3DCP prefab; B3 - Cast on-site; B4 - Cast prefab.

A detailed review of the raw material acquisition stage revealed that cement production accounts for most of the impacts, ranging from 58 to $76 \%$ of the single score. This is followed by the production of reinforcing steel which ranges from $11 \%$ to $27 \%$. The remainder is the sum of other materials and processes, which contributed to roughly $15 \%$ of the total impact of the materials stage (Fig. 10). 

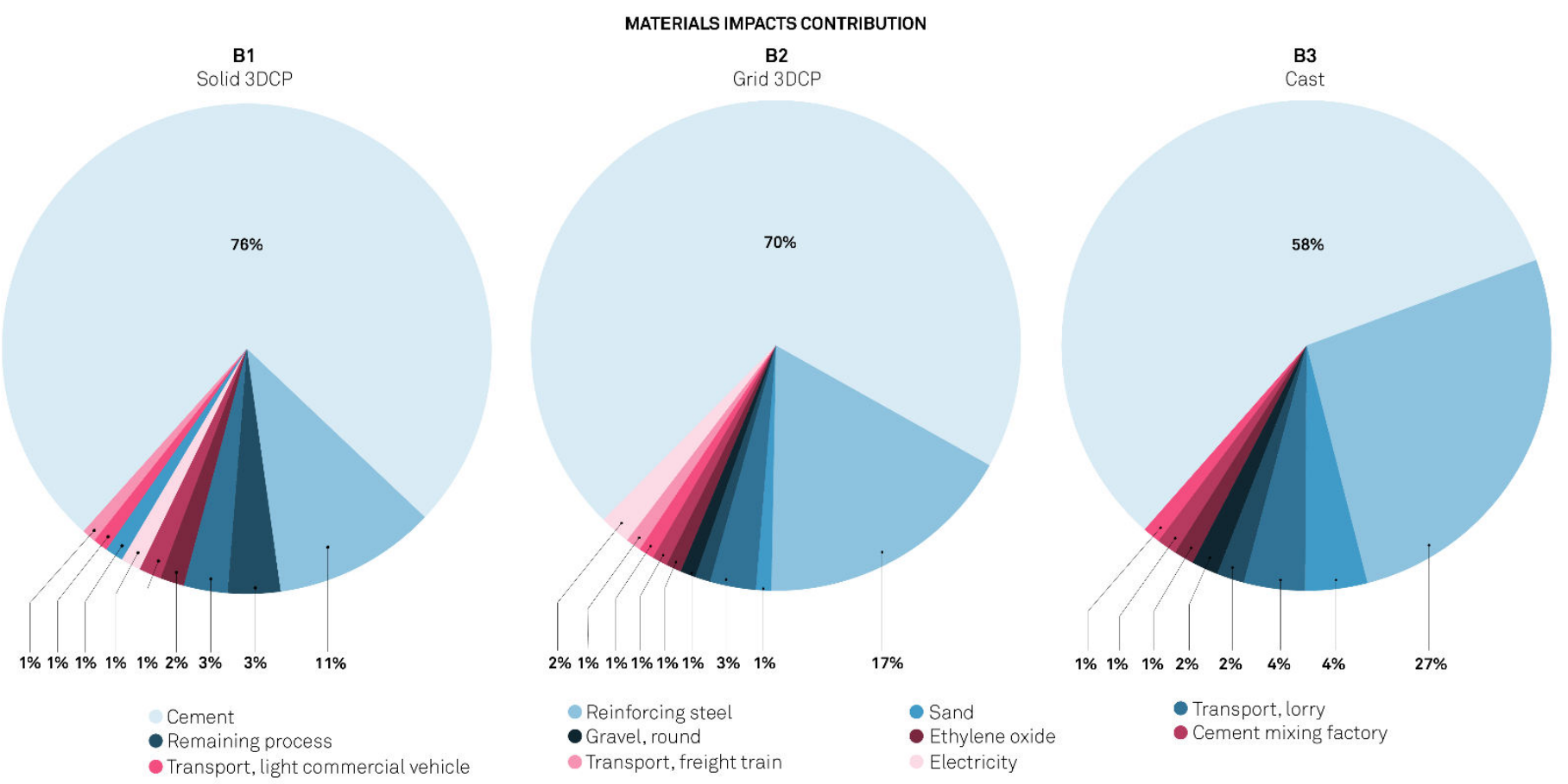

Fig. 10. Single score contribution from materials and materials production processes.

\subsection{Sensitivity Analysis}

According to the sensitivity analysis results (Fig. 11), the impact of recarbonation varies approximately between $7 \%$ and $34 \%$ based on the correction factors assumed in the recarbonation model proposed by Lagerblad (2005). As the maximum recarbonation is reached in the assumed lifetime for $B 2$, no improvement can be outlined in the best-case scenario.

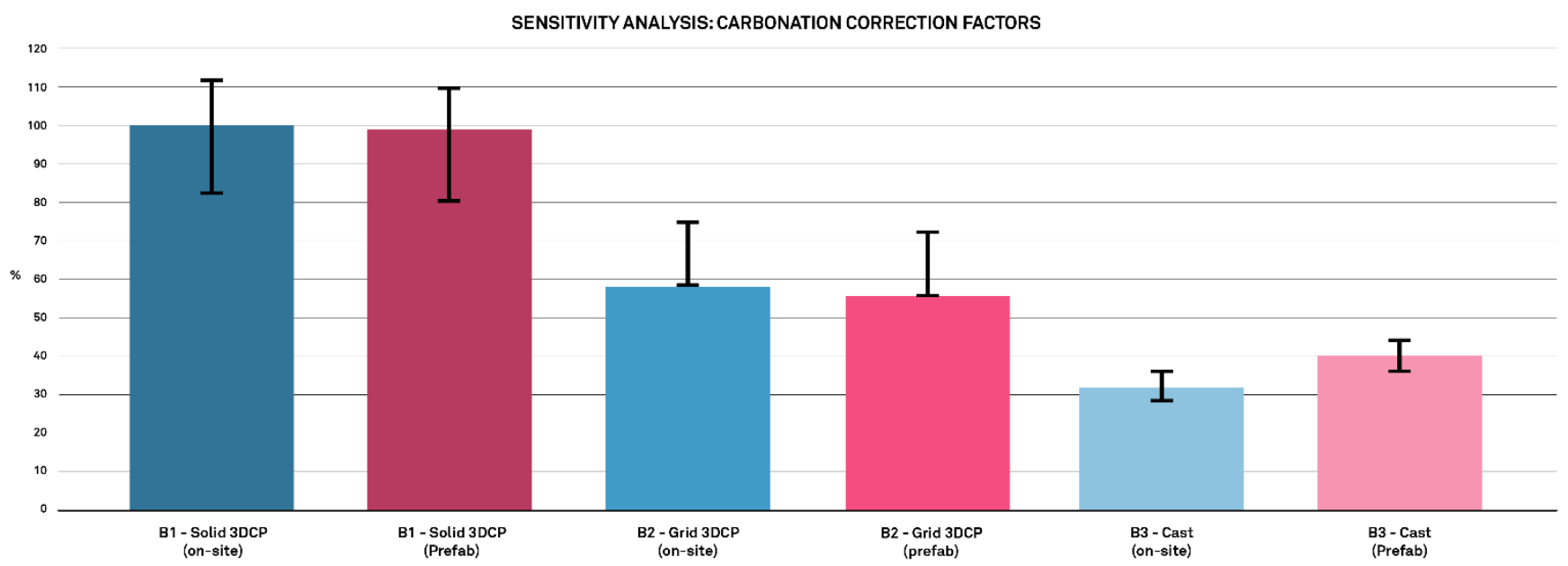

Fig. 11. Variation in climate change impacts in best and worst-cases of recarbonation correction factors compared to reference results

The clinker content has a high effect on the impacts, e.g. approximately $20 \%$ on climate change. Certain categories, e.g. land use, display a relatively low impact variation (Fig. 12a). Overall, the solid 3DCP beams present high variation, with specific impact categories more sensitive for all beams, such as the mineral resources use impact category. 
The transportation distance from manufacturer to construction site has a great influence on the systems, with the highest magnitude on the on-site beams, which is due to the transportation of 2.5 tons of manufacturing equipment. GHG emissions show an increase of up to $30 \%$ in the worst-case, whereas the best-case leads to a decrease of up to $10 \%$ (Fig. 12b).

The reuse of manufacturing equipment is generally insignificant for the results. However, the on-site cast beam has a high environmental impact in the worst-case scenario, where the formwork is not reused. In the best case of 100 reuses, the on-site cast beam is comparable to the other beams (Fig. 12c). Recycling the manufacturing equipment has a relatively low impact in most categories, with the exceptions of water use and land use. The energy use for the robot and pump has a negligible effect when comparing the best and worst-case scenarios.

Current environmental climate change potential issues associated with the 3DCP technology lie in the higher use of cement, which results in required material savings of $59 \%$ for prefabricated beams and $63 \%$ for on-site produced beams to reach a breakeven of emissions compared to traditional cast beam. Overall, a cast beam made from reusable steel formwork presents the lowest total potential environmental impact. B2 beams have a $43 \%$ lower climate change impact than B1.

According to the sensitivity analysis results, the clinker content variation is one of the main factors influencing the impact assessment. For recarbonation, the differing cases alter the offset of $\mathrm{CO}_{2}$ eq. emissions up to $30 \%$, which indicates that more accurate modeling of recarbonation in concrete is essential to be considered in the LCAs of concrete construction elements. Transportation mainly affects the 3DCP on-site systems, only partially affecting the other comparisons. The end-of-life and reuse of the manufacturing equipment do not have a significant effect in any but one situation, i.e. on-site cast-concrete formwork. For the reuse of plywood formwork used for on-site cast-concrete, the difference in the number of emissions, when comparing the low (1) and 

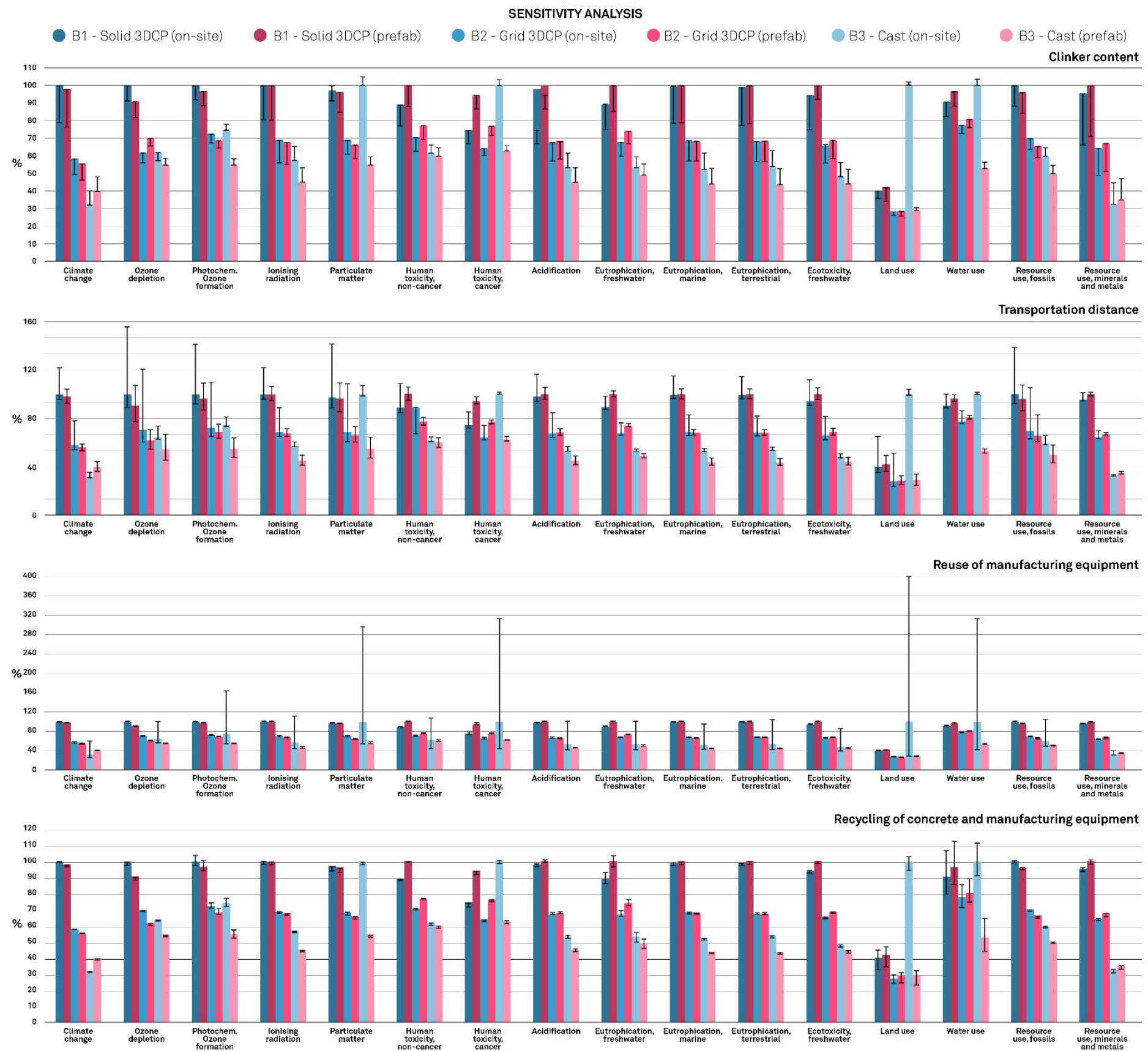

Fig. 12. Variation in midpoint results considering best and worst-cases of uncertainty within categories: a) clinker content in cement; b) transportation distance; c) reuse of manufacturing equipment; d) recycling of concrete and manufacturing equipment.

\section{Discussion}

The results of this study show that for geometrically standard short-span reinforced concrete beams, conventional casting has lower emissions compared to the current state of reinforced 3DCP. The hotspot analysis of the midpoint impact categories for 3DCP highlights that manufacturing and transportation combined accounts for only approximately $10 \%$ of the impacts, while the remaining amounts are due largely to the cement and its production. Given the achieved structural performance and the proportionally larger amounts of clinker present in the 3DCP mix, i.e. 33\% more than for the cast beams in the current work, material savings of approximately $60 \%$ for both on-site and prefabricated 3DCP beams are required to reach a breakeven of emissions with 
conventionally cast beams. Nevertheless, the results highlight that, from a single score perspective, the gap in global impacts between 3DCP and cast beams is reduced by up to about $30 \%$, with disposable formworks in a single score perspective.

The lightweight 3DCP beam solution introduced in this study shows potential in terms of overall environmental impact. B2 - Grid $3 D C P$, in a weighted single score comparison, presented about $45 \%$ less global impacts when compared to $B 1$ - Solid $3 D C P$. This is explained by the lower amount (approximately 25\%) of cement employed, but also by the positive effects of recarbonation, which can reduce the carbon emissions by up to $30 \%$ more than the solid design. This is achieved thanks to the porous design made possible by the specific control on the material deposition offered by 3DCP.

Overall, the impacts from onsite and prefab productions have been found to be equivalent on a single score perspective for both production technologies. Nevertheless, the Midpoint Analysis results show, on average, about 20\% higher impacts for the on-site construction process as compared to prefab for the conventionally cast beams.

The results highlight the relevance of including the Use and the Disposal stages into a Cradle-to-Grave LCA for concrete structures. The hotspot analysis (Fig. 9) shows that the Use Stage, through recarbonation, has impacts for $-10 \%$ on climate change, which can become as high as $-30 \%$ from the results of the Sensitivity Analysis (Fig. 11). The Disposal phase brings an impact of approximately $10-20 \%$ in most categories, however as low as $-58 \%$ for human toxicity, cancer. This is due to the assumed partial recycling of the used materials, i.e. steel and gravel, overperforming the impact of transport and processing of the disposed of elements. The impacts of the Use and Disposal stages are novel findings that are not included in the results of the existing literature at the time of writing. Nevertheless, some general environmental considerations found in the literature regarding the application of 3DCP are confirmed. The results of this study align with Alhumayani et al. (2020) and Mohammad et al. (2020) both reporting 75-80\% of the impact attributed to cement, which corresponds to the $76 \%$ of $\mathrm{B} 1$ assessed in this work. Moreover, they also highlight $25 \%$ higher $\mathrm{CO}_{2}$ eq emissions generated by the 3DCP process altogether, which corresponds to the prefab results found in this research and are only slightly lower than that of the on-site approach (33\%).

\subsection{Limitations of the study}

The requirement of a well-defined FU in comparative LCA implied the use of a simple beam geometry for a fair comparison between the 3DCP and a formwork-based technique that would allow its reuse. As the main competitive advantage of 3DCP lies in its capability to design relatively more complex and customized solutions, the current setup limits the potential of 3DCP for better environmental performance. This is because the innovative nature of the 3DCP process potentially brings hybrid functional possibilities, e.g. integration of beam and slab, integration of technical cavities, that would exploit even further the technology and emphasize its positive environmental impacts. 
The specific testing campaign performed on the 3DCP beams and the general lack of simulation and calculation models for this new technology poses a degree of uncertainty in comparison to the well-established cast-concrete structural element taken into account for the assessment. As the FU of comparison is based on the test data, this could have an influence on the results.

The sensitivity analysis highlights that the main uncertainties in climate change related to the clinker content of the cement with the best-case having $23 \%$ lower climate change compared to the worst case. The largest uncertainties for the cast beams lie in the reuse of manufacturing equipment, e.g. land use, that can increase up to $400 \%$. A better definition of the clinker content amounts and of the reuse scenario would benefit from a statistical analysis of real-case applications.

The modeling of recarbonation was calculated through a simplified model, which carries a level of uncertainty in the results dependent on the applied constants (about $-18 \%$ to $+12 \%$ ). Given the impact of recarbonation revealed by the results, accurate modeling of this phenomenon should be paid due attention in future research.

As disposal is expected at the end of the beam lifetime, the characterization factors and impacts may have changed. This is an inherent methodological limitation of LCA.

\section{Strategies for enhancing the environmental sustainability of 3DCP}

The findings of the presented work indicate that the largest environmental impact of 3DCP is due to the use of materials, and reducing the related emissions requires improvements in design and material development.

Guidelines for material development encompasses:

- Development of reinforcements methods for 3DCP: As an upcoming and developing construction technique, methods for reinforcing printed concrete structures are still experimental. The use of conventional steel rebars, which account for up to $23 \%$ of the material impact, proved to generally fulfill structural requirements. Future studies on reinforcements should focus on enhancing the structural efficiency of reinforced 3DCP, and in turn, reducing the use of both concrete and steel to achieve optimal structural performance.

- Concrete aggregates: Cement has the highest environmental impact on the LCA of 3DCP. Future research should study manufacturing processes for the extrusion of cement mixes with larger aggregates, to reduce the clinker content.

- Low-carbon concrete: Sustainable low-clinker cement alternatives (Bhattacherjee et al. 2021) that reduce the environmental impact of the 3DCP material are strategic. Current studies are already focusing on this area ranging from limestonecalcinated clay-based cementitious mixes (Chen 2021) to the recycling of concrete as aggregates (Bai 2021).

Guidelines for the design advancements in 3DCP structures include: 
- Design for recarbonation: This paper introduced a strategy for lightweight concrete structures based on a porous grid design. This design increases the exposed surface area by $300 \%$ in $B 2$ - Grid 3DCP compared to the B1 and B3, favoring the recarbonation process. If correctly addressed in the design process, layer-based porous structures shall be taken into account as a long-term carbon sequestration strategy that fits well with the expected lifetime of concrete structures (Fig.13).

- Shape optimization: In this study, we have adopted a regular beam shape with a constant section to reduce the number of design variables in comparison. In principle, shape optimization can be both performed with printing and casting. However, 3DCP has much higher fabrication flexibility for almost no cost, while cast beams demand custom disposable formwork accounting for up to $75 \%$ of the concrete structure's cost (García de Soto 2018). This practically translated into much higher design freedom achievable through 3DCP, which points to a large potential for future investigation in the shape optimization of horizontal structures, targeting a reduction of the concrete mass to about $60 \%$ to outperform casted beams.

- Bespoke Design: The use of 3DCP generates a lower environmental impact when employed for manufacturing custom or non-standard concrete elements. In such cases, cast concrete involves a specific formwork design with an increase of ten times in land use, about six times in particulate matter, and between 100 and 1 reuses in climate change under the on-site scenario. The prefab casting scenario assumes that the use of steel formworks is hardly feasible for one-off applications.
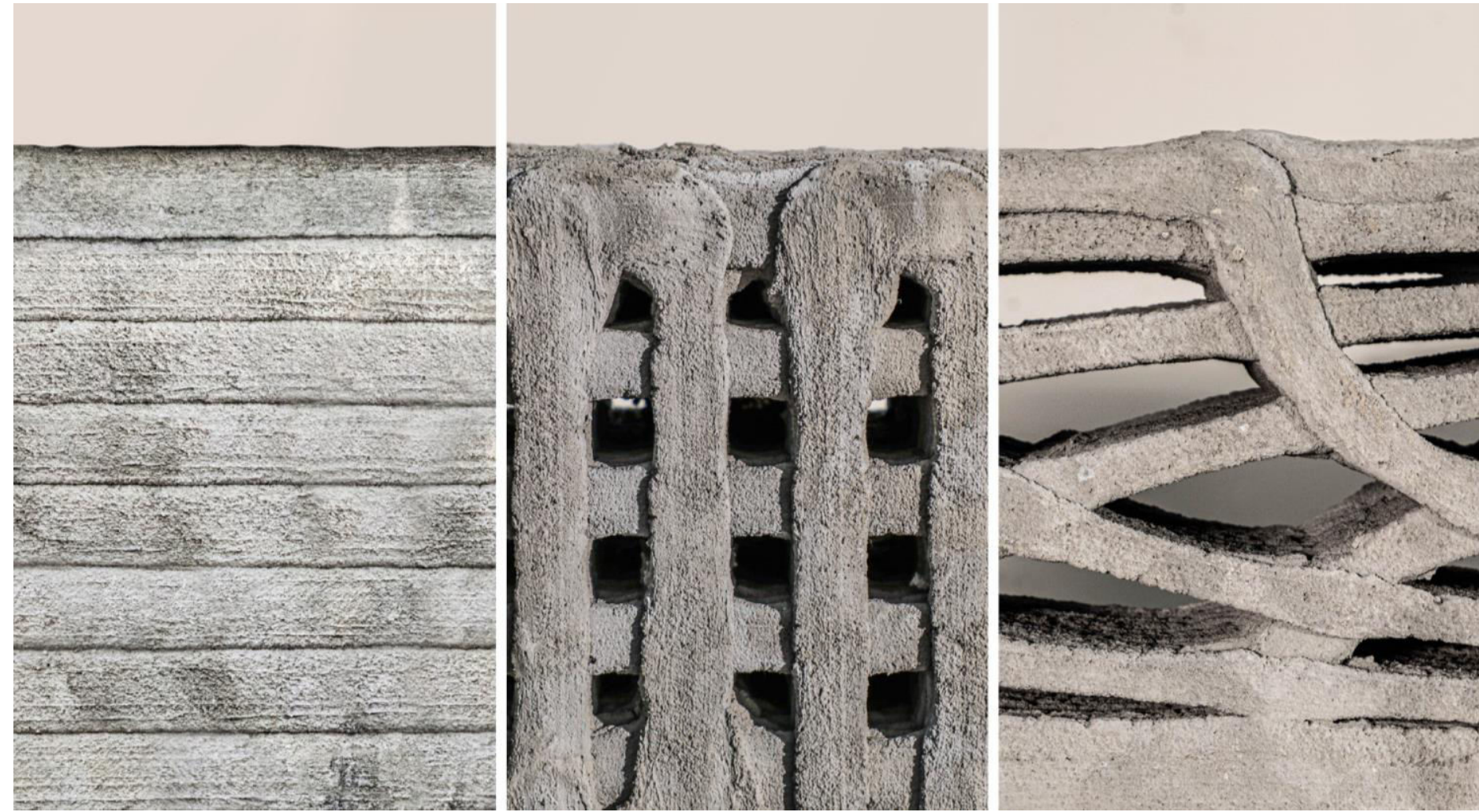
Fig. 13. Detail of optimized toolpath layouts of beam prototypes from the 3DLightBeam project from CREATE

\section{Acknowledgments}

The experimental work on 3DCP was carried out at the CREATE Lab at the University of Southern Denmark - Section for Civil and Architectural Engineering, in cooperation with the industrial partner Hyperion Robotics. The structural data in this paper are obtained from structural experiments conducted in collaboration with the Structures Group at the University of Southern Denmark Section for Civil and Architectural Engineering led by Assoc. Prof. Dr. Henrik Brøner Jørgensen. The authors wish to thank the project partners Saint Gobain Weber Denmark (mortar material), Fosroc (concrete admixtures), and Danish Fibres (polypropylene fibers). The authors wish to thank Lisa Lisberg Sand, design engineer at concrete element manufacturer Spaencom A/S, for the supplied insights in concrete prefabrication production practices. Burak Sen and Gang Liu acknowledge the Independent Research Fund Denmark (via the project iBuildGreen) for financial support.

\section{Declaration of Funding and Interests}

This research did not receive any specific grant from funding agencies in the public, commercial, or not-for-profit sectors.

\section{Data Availability Statement}

The datasets generated during and/or analysed during the current study are partially included as Supplementary Information to the manuscript, and fully available from the corresponding author on reasonable request.

\section{References}

Agustí-Juan, I., Müller, F., Hack, N., Wangler, T., Habert, G., 2017. Potential benefits of digital fabrication for complex structures: Environmental assessment of a robotically fabricated concrete wall. J Clean Prod 154, 330-340. https://doi.org/10.1016/j.jclepro.2017.04.002

Alhumayani, H., Gomaa, M., Soebarto, V., Jabi, W., 2020. Environmental assessment of large-scale 3D printing in construction: A comparative study between cob and concrete. J Clean Prod. 270. https://doi.org/10.1016/j.jclepro.2020.122463

Allwood, Julian M., et al. 2011. Material efficiency: A white paper. Resour Conserv Recycl 55.3. 362-381.

Anell, L., 2015. Concrete 3d printer. 2015. M.Sc. Thesis Product Development. Lund University

Anton, A., Reiter, L., Wangler, T., Frangez, V., Flatt, R. J., \& Dillenburger, B., 2021. A 3D concrete printing prefabrication platform for bespoke columns. Autom Constr, 122, 103467. https://doi.org/10.1016/j.autcon.2020.103467

Bai, G., Wang, L., Ma, G., Sanjayan, J., Bai, M. 2021. 3D printing eco-friendly concrete containing under-utilised and waste solids as aggregates. Cem Concr Compos, 120(-): 104037.

Barcelo, L., Kline, J., Walenta, G., Gartner, E., 2014. Cement and carbon emissions. Mater Struct 47, $1055-1065$. https://doi.org/10.1617/s11527-013-0114-5 
Bhattacherjee, S., Basavaraj, A.S., Rahul, A.V., Santhanam, M., Gettu, R., Panda, B., Schlangen, E., Chen, Y., Copuroglu, O., Ma, G., Wang, L., Beigh, M.A.B., Mechtcherine, V., 2021. Sustainable materials for 3D concrete printing. Cem Concr Compos (122). DOI: 10.1016/j.cemconcomp.2021.104156

Bos, F., Wolfs, R., Ahmed, Z., Salet, T., 2016. Additive manufacturing of concrete in construction: potentials and challenges of 3D concrete printing. Virtual Phys Prototyp 11, 209-225. https://doi.org/10.1080/17452759.2016.1209867

Breseghello, L., Naboni, R., 2021a. Adaptive Toolpath: Enhanced Design and Process Control for Robotic 3DCP, in: Proceedings of the CAAD Futures 2021. Los Angeles.

Breseghello, L., Naboni, R., 2021b. Toolpath Simulation, Design and Manipulation in Robotic 3D Concrete Printing. In: Proceedings of PROJECTIONS, in: Proceedings of PROJECTIONS - 26th International Conference of the Association for Computer-Aided Architectural Design Research in Asia (CAADRIA). Hong Kong.

Burger, J., Lloret-Fritschi, E., Scotto, F., Demoulin, T., Gebhard, L., Mata-Falcón, J., Gramazio, F., Kohler, M., Flatt, R.J., 2020. Eggshell: Ultra-Thin Three-Dimensional Printed Formwork for Concrete Structures. 3D Print Addit Manuf 7, 48-59. https://doi.org/10.1089/3dp.2019.0197

Buswell, R.A., Leal de Silva, W.R., Jones, S.Z., Dirrenberger, J., 2018. 3D printing using concrete extrusion: A roadmap for research. Cem Concr Res 112, 37-49. https://doi.org/10.1016/j.cemconres.2018.05.006

Buswell, R., da Silva, W. R. L., Bos, P., Schipper, R., Lowke, D., Hack, N., Kloft, H., Mechtcherine, V., Wangler, T., \& Roussel, N., 2020. A process classification framework for defining and describing digital fabrication with concrete. Cem Concr Res 134(December2019). https://doi.org/10.1016/j.cemconres.2020.106068

Cao, Z, Myers, RJ, Lupton, RC, Duan, H, Sacchi, R, Zhou, N, Reed Miller, T, Cullen, JM, Ge, Q \& Liu, G. 2020. The sponge effect and carbon emission mitigation potentials of the global cement cycle. Nat Commun 11, 1, 3777. https://doi.org/10.1038/s41467-020-17583-w

Chandra Paul, S., van Zijl, G.P.A.G., Tan, M.J., Gibson, I., 2018. A review of 3D concrete printing systems and materials properties: current status and future research prospects. Rapid Prototyp J 24. https://doi.org/10.1108/RPJ-09-2016-0154

Chen, Y. 2021. Investigation of limestone-calcined clay-based cementitious materials for sustainable 3d concrete printing. Master Thesis, Materials and Environment. TU Delft.

Cho, H.-W., Roh, S.-G., Byun, Y.-M., Yom, K.-S. 2004. Structural Quantity Analysis of Tall Buildings. Proceedings of the CTBUH 2004 Seoul Conference.

COBOD. Construction Of Building on Demand. 2021. https://cobod.com/ Accessed 18.09.21.

CyBe. CyBe Construction, We redefine construction, 2021. www.cybe.eu. Accessed 17.09.21

Dansk Standard, 2008. Eurocode 2: Design of concrete structures - Part 1-1: General rules and rules for buildings. Nordhavn.

de Schutter, G., Lesage, K., Mechtcherine, V., Nerella, V.N., Habert, G., Agusti-Juan, I., 2018. Vision of 3D printing with concrete Technical, economic and environmental potentials. Cem Concr Res 112. https://doi.org/10.1016/j.cemconres.2018.06.001

Eberhardt, L.C.M., Stijn, A. van, Rasmussen, F.N., Birkved, M., Birgisdottir, H., 2020. Towards circular life cycle assessment for the built environment: A comparison of allocation approaches. IOP Conference Series: Earth and Environmental Science 588. https://doi.org/10.1088/1755$1315 / 588 / 3 / 032026$

Ecoinvent, 2020. EcoInvent Database.

European Commission, 2021. 2030 climate \& energy framework [WWW Document]. EU Climate Action webportal. URL https://ec.europa.eu/clima/policies/strategies/2030 (accessed 5.28.21).

Gan, V.J.L., Wong, C.L., Tse, K.T., Cheng, J.C.P., Lo, I.M.C., Chan, C.M., 2019. Parametric modelling and evolutionary optimization for costoptimal and low-carbon design of high-rise reinforced concrete buildings. Adv Eng Inform 42, 100962. https://doi.org/10.1016/j.aei.2019.100962

García de Soto, B., Agustí-Juan, I., Hunhevicz, J., Joss, S., Graser, K., Habert, G., \& Adey, B. T. 2018. Productivity of digital fabrication in construction: Cost and time analysis of a robotically built wall. Autom Constr 92, 297-311. https://doi.org/10.1016/j.autcon.2018.04.004 
Gebhard, L., Mata-Falcon, J., Anton, A., Dillenburger, B., \& Kaufmann, W., 2021. Structural behaviour of 3D printed concrete beams with various reinforcement strategies. Eng Struct 240, 10.2020. https://doi.org/10.1016/j.engstruct.2021.112380

Hatfield, A., 2021. Cement. U.S. Geological Survey, Mineral Commodity Summaries, January 2021.

ICON. 2021. https://www.iconbuild.com/ Accessed 28.09.21

IEA, 2018. Technology Roadmap - Low-Carbon Transition in the Cement Industry. Paris.

IEA, 2020. Cement [WWW Document]. IEA Website. URL https://www.iea.org/reports/cement (accessed 10.14.21).

Joergensen, H., Douglas, P., Naboni, R., 2021. Experimental Study on the Anisotropic Behaviour and Strength of 3D Printed Concrete, In: Concrete Structures: New Trends for Eco-Efficiency and Performance. Lisbon.

Labonnote, N., Rønnquist, A., Manum, B., \& Rüther, P., 2016. Additive construction: State-of-the-art, challenges and opportunities. Autom Constr, 72, 10.2017, 347-366. https://doi.org/10.1016/j.autcon.2016.08.026

Lagerblad, B., 2005. Carbon Dioxide Uptake During Concrete Life Cycle: State of the Art. Swedish Cement and Concrete Research Institute.

Lei, Y., Zhang, Q., Nielsen, C., He, K., 2011. An inventory of primary air pollutants and CO2 emissions from cement production in China, 1990-2020. Atmos Environ 45, 147-154. https://doi.org/10.1016/j.atmosenv.2010.09.034

Mani, M., Lyons, K.W., Gupta, S.K., 2014. Sustainability Characterization for Additive Manufacturing. J Res Natl Inst Stand Technol 119, 419. https://doi.org/10.6028/jres.119.016

Miller, S.A., Horvath, A., Monteiro, P.J.M., 2016. Readily implementable techniques can cut annual CO2 emissions from the production of concrete by over 20\%. Environ Res Lett 11. https://doi.org/10.1088/1748-9326/11/7/074029

Mohammad, M., Masad, E., Al-Ghamdi, S.G., 2020. 3D Concrete Printing Sustainability: A Comparative Life Cycle Assessment of Four Construction Method Scenarios. Buildings 10. https://doi.org/10.3390/buildings10120245

Naboni, R., Breseghello, L., 2020. High-Resolution Additive Formwork for Building-Scale Concrete Panels, in: Second RILEM International Conference on Concrete and Digital Fabrication. https://doi.org/1007/978-3-030-49916-7_91

Naboni, R., Breseghello, L., 2019. Additive Formwork for Concrete Shell Constructions, in: Form and Force - IASS Symposium 2019. Barcelona.

Naboni, R., Breseghello, L., Kunic, A., 2019. Multi-scale design and fabrication of the Trabeculae Pavilion. Addit Manuf 27. https://doi.org/10.1016/j.addma.2019.03.005

Nerella, V.N., Mechtcherine, V., 2019. Studying the Printability of Fresh Concrete for Formwork-Free Concrete Onsite 3D Printing Technology (CONPrint3D), in: 3D Concrete Printing Technology. Elsevier, 333-347. https://doi.org/10.1016/B978-0-12-815481-6.00016-6

Panesar, D.K., Seto, K.E., Churchill, C.J., 2017. Impact of the selection of functional unit on the life cycle assessment of green concrete. The Int J Life Cycle Assess 22, 1969-1986. https://doi.org/10.1007/s11367-017-1284-0

Panda, B., Chandra Paul, S., \& Jen Tan, M. (2017). Anisotropic mechanical performance of 3D printed fiber reinforced sustainable construction material. Mater Lett, 209, 146-149. https://doi.org/10.1016/j.matlet.2017.07.123

Pedersen, L.G., Ottosen, L.M., 2019. Skrøner om genbrug af gammel beton skal fakta-tjekkes [WWW Document]. DTU Website. URL https://www.dtu.dk/nyheder/Nyhed?id=\%7B986ABAA8-CFD2-4BC5-AA0B-C978D4C160FA\%7D (accessed 5.30.21).

Perrot, A., 2019. 3D Printing of Concrete - State of the Art and Challenges of the Digital Construction Revolution. A. Perrot (ed.). https://doi.org/10.1002/9781119610755

PolyStruc, 2021. PolyBeam. https://www.polystruc.com Accessed 08.08.2021

Salet, T. A. M., Ahmed, Z. Y., Bos, F. P., \& Laagland, H. L. M., 2018. 3D Printed Concrete Bridge. Proceedings of the International Conference on Progress in Additive Manufacturing, 2018-May, 2-9. https://doi.org/10.25341/D4530C 
Slack, N., Brandon-Jones, A., Johnston, R., 2013. Operations Management, 7th ed. Pearson, Harlow.

Suiker, A. S. J., 2018. Mechanical performance of wall structures in 3D printing processes: Theory, design tools and experiments. Int J Mech Sci 137, 10.2017, 145-170. https://doi.org/10.1016/j.ijmecsci.2018.01.010

Vantyghem, G., de Corte, W., Shakour, E., Amir, O., 2020. 3D printing of a post-tensioned concrete girder designed by topology optimization. Autom Constr 112, 103084. https://doi.org/10.1016/j.autcon.2020.103084

Vertico3D, concrete printing. 2021. https://www.vertico.xyz/. Accessed 12.09.21

Venkat Rao, N., Meena, T., 2017. A review on recarbonation study in concrete. IOP Conference Series: Mat Sci Eng 263. https://doi.org/10.1088/1757-899X/263/3/032011

Weng, Y., Li, M., Ruan, S., Wong, T.N., Tan, M.J., Ow Yeong, K.L., Qian, S., 2020. Comparative economic, environmental and productivity assessment of a concrete bathroom unit fabricated through 3D printing and a precast approach. J Clean Prod 261 , 121245. https://doi.org/10.1016/j.jclepro.2020.121245

Wight, J.K., Macgregor, J.G., 2011. Reinforced Concrete: Mechanics and Design, 6th ed. Pearson Education, New Jersey.

WinSun. Yingchuang Building Technique （Shanghai）Co.Ltd. (WinSun). 2021. http://www.winsun3d.com/En/ Accessed 08.09.2021

Xi, F., Davis, S.J., Ciais, P., Crawford-Brown, D., Guan, D., Pade, C., Shi, T., Syddall, M., Lv, J., Ji, L., Bing, L., Wang, J., Wei, W., Yang, K.H., Lagerblad, B., Galan, I., Andrade, C., Zhang, Y., Liu, Z., 2016. Substantial global carbon uptake by cement recarbonation. Nat Geosci 9. https://doi.org/10.1038/ngeo2840

XtreeE. The large scale 3d. https://xtreee.com/ Accessed 19.09.21.

Zhang, C., Hu, M., Dong, L., Gebremariam, A., Miranda-Xicotencatl, B., di Maio, F., Tukker, A., 2019. Eco-efficiency assessment of technological innovations in high-grade concrete recycling. Resour Conserv Recycl 149. https://doi.org/10.1016/j.resconrec.2019.06.023 


\section{Supplementary Files}

This is a list of supplementary files associated with this preprint. Click to download.

- SupportingInformation.docx 